\title{
Assessment of Central Airway Obstruction Using Impulse Oscillometry Before and After Interventional Bronchoscopy
}

\author{
Hiroshi Handa MD PhD, Jyongsu Huang PhD, Septimiu D Murgu MD, \\ Masamichi Mineshita MD PhD, Noriaki Kurimoto MD PhD, Henri G Colt MD, \\ and Teruomi Miyazawa MD PhD
}

\begin{abstract}
BACKGROUND: Spirometry is used to physiologically assess patients with central airway obstruction (CAO) before and after interventional bronchoscopy, but is not always feasible in these patients, does not localize the anatomic site of obstruction, and may not correlate with the patient's functional impairment. Impulse oscillometry may overcome these limitations. We assessed the correlations between impulse oscillometry measurements, symptoms, and type of airway narrowing, before and after interventional bronchoscopy, and whether impulse oscillometry parameters can discriminate between fixed and dynamic CAO. METHODS: Twenty consecutive patients with CAO underwent spirometry, impulse oscillometry, computed tomography, dyspnea assessment, and bronchoscopy, before and after interventional bronchoscopy. The collapsibility index (the percent difference in airway lumen diameter during expiration versus during inspiration) was calculated using morphometric bronchoscopic images during quiet breathing. Variable CAO was defined as a collapsibility index of $>\mathbf{5 0} \%$. Fixed CAO was defined as a collapsibility index of $<50 \%$. The degree of obstruction was analyzed with computed tomography measurements. RESULTS: After interventional bronchoscopy, all impulse oscillometry measurements significantly improved, especially resistance at $5 \mathrm{~Hz}$, which decreased from $0.67 \pm 0.29 \mathrm{kPa} / \mathrm{L} / \mathrm{s}$ to $0.38 \pm 0.17 \mathrm{kPa} / \mathrm{L} / \mathrm{s}(P<.001)$, and reactance at $20 \mathrm{~Hz}$, which increased from $-0.09 \pm 0.11$ to $0.03 \pm 0.08(P<.001)$. Changes in dyspnea score correlated with resistance at $5 \mathrm{~Hz}$, the difference between the resistance at $5 \mathrm{~Hz}$ and the resistance at $20 \mathrm{~Hz}$, and the reactance at $5 \mathrm{~Hz}$, but not with spirometry measurements. The type of obstruction also correlated with dyspnea score, and showed distinct impulse oscillometry measurements. CONCLUSIONS: Impulse oscillometry measurements correlate with symptom improvements after interventional bronchoscopy. Impulse oscillometry might be useful to discriminate variable from fixed central airway obstruction. (University Hospital Medical Information Network, http://www.umin.ac.jp/english, ID000005322). Key words: impulse oscillometry; respiratory resistance; respiratory reactance; morphometric bronchoscopy; interventional bronchoscopy; central airway obstruction; airway stent. [Respir Care 2014;59(2):231-240. ( 2014 Daedalus Enterprises]
\end{abstract}

\section{Introduction}

The traditional assessment of central airway obstruction (CAO) involves spirometry, bronchoscopy, and computed

Drs Handa, Mineshita, and Miyazawa are affiliated with the Division of Respiratory and Infectious Diseases, Department of Internal Medicine, and Dr Kurimoto is affiliated with the Division of Chest Surgery, Department of Surgery, St Marianna University School of Medicine, Kanagawa, Japan. Dr Huang is affiliated with the Department of Respiratory Medicine, Kanazawa Medical University, Ishikawa, Japan. Dr Murgu is affiliated with the Division of Pulmonary and Critical Care Medicine,
Department of Medicine, University of Chicago, Chicago, Illinois. Dr Colt is affiliated with the Division of Pulmonary and Critical Care Medicine, Department of Medicine, University of California, School of Medicine, Orange, California.

The authors have disclosed no conflicts of interest.

Dr Handa presented a version of this paper at the 19th European Respiratory Society Annual Congress held September 12-16, 2009, in Vienna, Austria, and at the American College of Chest Physicians Annual Meeting, held October 30 through November 4, 2010, in Vancouver, British Columbia, Canada. 
tomography (CT). ${ }^{1-5}$ From the physiologic standpoint, results from published studies show that pulmonary function tests are useful in the diagnosis of CAO and that flowvolume curves can detect and distinguish variable $\mathrm{CAO}$ from fixed CAO. ${ }^{6,7}$ In addition to diagnosis, however, the localization of flow-limiting bronchial segments is relevant for treatment decisions in all cases of CAO (fixed or dynamic). In a previous study we identified flow-limiting segments in the central airways using a combination of flow-volume curves, bronchoscopy, endobronchial ultrasonography, and CT. ${ }^{5}$ More recently, we described novel multimodality imaging and physiologic studies to assess airway wall structure, identify changes in flow-limiting segments before and after treatment, and provide insight into the pathogenesis of expiratory central airway collapse. ${ }^{6}$ Spirometry, however, is not always feasible in patients with $\mathrm{CAO}$, due to patient-related factors that disallow or interfere with an optimal forced expiratory maneuver. These include but are not limited to severe dyspnea, cough, fatigue, language barrier, cooperation, and cognitive impairment. Furthermore, in patients with $\mathrm{CAO}$, flow-volume curves are characteristic when severe obstruction occurs, ${ }^{8}$ and spirometry values may not correlate with the degree of airway narrowing. ${ }^{9}{ }^{910}$ Even when diagnostic for CAO, spirometry cannot localize the site of obstruction. ${ }^{5}$

Impulse oscillometry is a type of forced oscillation technique that enables pulmonary function tests to be performed during quiet breathing, ${ }^{11,12}$ and is effortindependent. Brief random pressure pulses of $5-35 \mathrm{~Hz}$, generated by a small loudspeaker mounted in series with a pneumotachometer, are applied during tidal breathing. Pressure-flow oscillations are superimposed on the tidal breaths, and the data provide an estimate of total respiratory system impedance, resistance, and reactance at different frequencies, which might differentiate between central and peripheral components of airway obstruction. ${ }^{12}$ The $5 \mathrm{~Hz}$ signal has slower cycle time and a larger wavelength, so it reaches the lung periphery and thus provides information about the entire respiratory tract. The $20 \mathrm{~Hz}$ signal has faster cycle time and a shorter wavelength and thus provides information about the proximal, larger airways. Therefore, an increased resistance at $5 \mathrm{~Hz}$ reflects an increase in total respiratory resistance, which suggests airway obstruction such as that found in patients with COPD, whereas a resistance increase at $20 \mathrm{~Hz}$ reflects

\footnotetext{
Correspondence: Septimiu D Murgu MD, Division of Pulmonary and Critical Care Medicine, Department of Medicine, University of Chicago, 5841 South Maryland Avenue, MC 6076, Chicago IL 60637. E-mail: tim.murgu@gmail.com.
}

DOI: $10.4187 /$ respcare.02094

\section{QUICK LOOK}

\section{Current knowledge}

Spirometry is used to assess central airway obstruction before and after interventional bronchoscopy. Spirometry cannot pinpoint the site of the obstruction.

\section{What this paper contributes to our knowledge}

Changes in impulse oscillometry findings after interventional bronchoscopy correlated with symptom improvement. Impulse oscillometry might help discriminate between variable and fixed airway obstruction, aiding in treatment decisions.

more specifically increased central airway resistance, such as that found in patients with $\mathrm{CAO}$, due to various causes. ${ }^{13}$ This technique was introduced in 1956 to measure respiratory resistance and respiratory reactance in humans, ${ }^{14}$ and has been employed to assess peripheral airway obstruction in children and adults with COPD or asthma. In case reports and small case series this technique proved useful for detecting CAO. ${ }^{15-18}$

We assessed the correlation between impulse oscillometry measurements, symptoms, and type of airway narrowing, before and after interventional bronchoscopy, and whether impulse oscillometry parameters can discriminate between fixed and dynamic CAO.

\section{Methods}

The ethics committee of St Marianna University School of Medicine approved this study, and all subjects gave informed consent.

\section{Subjects}

Twenty consecutive patients with CAO confirmed via bronchoscopy and chest CT were recruited at St Marianna University in Kawasaki, Japan, between April 2008 and December 2010. Before and after interventional bronchoscopy to restore airway patency, all the subjects underwent impulse oscillometry, spirometry, dyspnea assessment (with the modified Medical Research Council dyspnea scale), and chest CT. The site of maximal obstruction in all 20 subjects was in the trachea, at the level of the main carina. We excluded 25 patients with CAO: in 12 patients impulse oscillometry could not be performed because of tracheotomy tube $(n=11)$ or endotracheal tube $(n=1)$, and the other 13 patients did not have impulse oscillometry measurements both before and after interventional bronchoscopy. These 13 patients with missing impulse oscillometry measurements could not perform impulse os- 
Table 1. Pulmonary Function Measurements, Bronchial Cross-Sectional Area, and Dyspnea Score Before and After Interventional Bronchoscopy in 20 Subjects With Central Airway Obstruction

\begin{tabular}{|c|c|c|c|}
\hline & Before & After & $P$ \\
\hline FVC, L & $2.40 \pm 0.79$ & $2.74 \pm 0.84$ & .35 \\
\hline $\mathrm{FEV}_{1}, \mathrm{~L}$ & $1.10 \pm 0.58$ & $1.93 \pm 0.74$ & .001 \\
\hline $\mathrm{PEF}, \mathrm{L} / \mathrm{s}$ & $2.09 \pm 0.93$ & $4.48 \pm 2.05$ & $<.001$ \\
\hline $\mathrm{FEF}_{50}, \mathrm{~L} / \mathrm{s}$ & $0.93 \pm 0.68$ & $1.87 \pm 0.91$ & .001 \\
\hline $\mathrm{FEF}_{25}, \mathrm{~L} / \mathrm{s}$ & $0.53 \pm 0.37$ & $0.80 \pm 0.54$ & .13 \\
\hline Resistance at $5 \mathrm{~Hz}, \mathrm{kPa} / \mathrm{L} / \mathrm{s}$ & $0.67 \pm 0.29$ & $0.38 \pm 0.17$ & $<.001$ \\
\hline Inspiration & $0.65 \pm 0.32$ & $0.36 \pm 0.18$ & $<.001$ \\
\hline Expiration & $0.68 \pm 0.30$ & $0.40 \pm 0.17$ & .001 \\
\hline Resistance at $20 \mathrm{~Hz}, \mathrm{kPa} / \mathrm{L} / \mathrm{s}$ & $0.38 \pm 0.09$ & $0.30 \pm 0.07$ & .04 \\
\hline Inspiration & $0.36 \pm 0.08$ & $0.27 \pm 0.07$ & .002 \\
\hline Expiration & $0.41 \pm 0.10$ & $0.32 \pm 0.07$ & .001 \\
\hline $\begin{array}{l}\text { Difference in resistance between } 5 \mathrm{~Hz} \text { and } \\
20 \mathrm{~Hz}, \mathrm{kPa} / \mathrm{L} / \mathrm{s}\end{array}$ & $0.27 \pm 0.22$ & $0.08 \pm 0.13$ & .002 \\
\hline Inspiration & $0.29 \pm 0.28$ & $0.09 \pm 0.14$ & .005 \\
\hline Expiration & $0.26 \pm 0.24$ & $0.08 \pm 0.13$ & .004 \\
\hline Reactance at $5 \mathrm{~Hz}, \mathrm{kPa} / \mathrm{L} / \mathrm{s}$ & $-0.35 \pm 0.37$ & $-0.15 \pm 0.11$ & .003 \\
\hline Inspiration & $-0.23 \pm 0.32$ & $-0.14 \pm 0.10$ & .012 \\
\hline Expiration & $-0.39 \pm 0.43$ & $-0.15 \pm 0.11$ & .004 \\
\hline Reactance at $20 \mathrm{~Hz}, \mathrm{kPa} / \mathrm{L} / \mathrm{s}$ & $-0.09 \pm 0.11$ & $0.03 \pm 0.08$ & $<.001$ \\
\hline Inspiration & $-0.10 \pm 0.11$ & $0.03 \pm 0.08$ & $<.001$ \\
\hline Expiration & $-0.10 \pm 0.13$ & $0.02 \pm 0.10$ & $<.001$ \\
\hline Resonance frequency, L/s & $26.20 \pm 9.80$ & $15.89 \pm 9.42$ & .002 \\
\hline Cross-sectional area, $\mathrm{m}^{2}$ & $52.3 \pm 31.8$ & $101.1 \pm 31.1$ & $<.001$ \\
\hline Dyspnea score* & $2.95 \pm 0.6$ & $1.45 \pm 0.5$ & $<.001$ \\
\hline $\begin{array}{l}\text { Values are mean } \pm \text { DD. } \\
* \text { Modified Medical Research Council dyspnea scale. } \\
P E F=\text { peak expiratory flow } \\
\mathrm{FEF}_{50}=\text { forced expiratory flow at } 50 \% \text { of the } \mathrm{FVC} \text { maneuver } \\
\mathrm{FEF}_{25}=\text { forced expiratory flow at } 25 \% \text { of the } \mathrm{FVC} \text { maneuver }\end{array}$ & & & \\
\hline
\end{tabular}

cillometry or any pulmonary function testing because of critical airway obstruction requiring emergency intervention. No patients were excluded because of language barrier or cognitive impairment.

\section{Spirometry}

Spirometry (Fudac-77, Fukuda Electronics, Tokyo, Japan) and impulse oscillometry (MasterScreen, CareFusion, San Diego, California) were performed according to the protocols of the European Respiratory Society. ${ }^{19} \mathrm{Im}$ pulse oscillometry was carried out before spirometry because forced expiration can affect resistance and reactance. The subjects were seated upright with their hands cradling their cheeks during quiet breathing for at least 5 breaths. Pressure pulses with frequencies from 5 to $35 \mathrm{~Hz}$ were generated by a small loudspeaker and were applied at the subject's mouth. We evaluated the following impulse oscillometry parameters: respiratory resistance at $5 \mathrm{~Hz}$, respiratory resistance at $20 \mathrm{~Hz}$, difference between the resistance at $5 \mathrm{~Hz}$ and the resistance at $20 \mathrm{~Hz}$ (resistance 5-20 Hz), reactance at $5 \mathrm{~Hz}$, reactance at $20 \mathrm{~Hz}$, and resonance frequency.

\section{Computed Tomography}

All subjects underwent $\mathrm{CT}$ in the supine position, during a breath-hold at deep inspiration, with a 64-detector CT scanner (Aquilion-64, Toshiba Medical, Tokyo, Japan). The cross-sectional area at the narrowest bronchial segment was measured with CT analysis software (Ziostation, Ziosoft, Tokyo, Japan). ${ }^{20}$

\section{Dyspnea Assessment}

The modified Medical Research Council dyspnea scale ranges from 0 to 4: 0 indicates shortness of breath with strenuous exercise, and 4 indicates breathlessness while dressing. ${ }^{21}$

\section{Interventional Bronchoscopy}

All subjects were intubated with a rigid bronchoscope (Efer-Dumon, Efer Medical, La Ciotat, France) under 
Table 2. Correlation Between Pre-Intervention Dyspnea Score* and Pulmonary Function Test Results

\begin{tabular}{|c|c|c|}
\hline & $\mathrm{R}$ & $P$ \\
\hline FVC & -0.31 & .19 \\
\hline $\mathrm{FEV}_{1}$ & -0.58 & .007 \\
\hline $\mathrm{PEF}$ & -0.69 & $<.001$ \\
\hline $\mathrm{FEF}_{50}$ & -0.58 & .007 \\
\hline $\mathrm{FEF}_{25}$ & -0.45 & .049 \\
\hline Resistance at $5 \mathrm{~Hz}$ & 0.74 & $<.001$ \\
\hline Inspiration & 0.70 & $<.001$ \\
\hline Expiration & 0.73 & $<.001$ \\
\hline Resistance at $20 \mathrm{~Hz}$ & 0.43 & .056 \\
\hline Inspiration & 0.45 & .046 \\
\hline Expiration & 0.53 & .02 \\
\hline Resistance at $5 \mathrm{~Hz}$ and $20 \mathrm{~Hz}$ & 0.74 & $<.001$ \\
\hline Inspiration & 0.69 & $<.001$ \\
\hline Expiration & 0.69 & $<.001$ \\
\hline Reactance at $5 \mathrm{~Hz}$ & -0.68 & .001 \\
\hline Inspiration & -0.53 & .02 \\
\hline Expiration & -0.73 & $<.001$ \\
\hline Reactance at $20 \mathrm{~Hz}$ & -0.71 & $<.001$ \\
\hline Inspiration & -0.68 & $<.001$ \\
\hline Expiration & -0.76 & $<.001$ \\
\hline Resonance frequency & 0.64 & .002 \\
\hline \multicolumn{3}{|c|}{$\begin{array}{l}\text { * The pre-intervention mean } \pm \mathrm{SD} \text { modified Medical Research Council dyspnea score was } \\
2.95 \pm 0.6 \text {. } \\
\mathrm{PEF}=\text { peak expiratory flow } \\
\mathrm{FEF}_{50}=\text { forced expiratory flow at } 50 \% \text { of the } \mathrm{FVC} \text { maneuver } \\
\mathrm{FEF}_{25}=\text { forced expiratory flow at } 25 \% \text { of the } \mathrm{FVC} \text { maneuver }\end{array}$} \\
\hline
\end{tabular}

general anesthesia. Rigid and flexible bronchoscopy (BF-1T260, BF-P260, and BF-XP260, Olympus, Tokyo, Japan) were performed on all subjects, to determine the narrowest airway segment during spontaneous breathing. Variable and fixed CAO were classified using morphometric bronchoscopy at the narrowest segment. ${ }^{22}$ The luminal area at the narrowest segment was calculated after the interventional bronchoscopy, using image analysis software (ImageJ, http://rsbweb.nih.gov/ij/index.html). The collapsibility index was defined as the difference in the airway lumen diameter between inspiration and expiration. A collapsibility index of $>50 \%$ was defined as variable $\mathrm{CAO}$, and $<50 \%$ was defined as fixed CAO. ${ }^{22}$

\section{Statistical Analysis}

All analyses were performed with statistics software (SAS 8.2, SAS Institute, Cary, North Carolina). Results are presented as mean $\pm \mathrm{SD}$. The difference between variable and fixed CAO was analyzed with the Mann-Whitney $\mathrm{U}$ test. Pulmonary function measurements and crosssectional area at the narrowest bronchial segment were analyzed with a non-parametric Wilcoxon signed-rank test. Differences were considered significant when the 2-tailed $P$ was $<.05$. The correlations between pulmonary func-
Table 3. Correlation Between Change in Dyspnea Score* and Pulmonary Function Test Results

\begin{tabular}{|c|c|c|c|}
\hline & $\begin{array}{c}\text { Change } \\
\text { mean } \pm \mathrm{SD}\end{array}$ & $\mathrm{R}$ & $P$ \\
\hline FVC & $0.34 \pm 0.70$ & 0.34 & .15 \\
\hline $\mathrm{FEV}_{1}$ & $0.83 \pm 0.81$ & 0.07 & .76 \\
\hline PEF & $2.39 \pm 1.87$ & 0.11 & .65 \\
\hline $\mathrm{FEF}_{50}$ & $0.95 \pm 0.91$ & 0.02 & .95 \\
\hline $\mathrm{FEF}_{25}$ & $0.28 \pm 0.42$ & -0.22 & .34 \\
\hline Resistance at $5 \mathrm{~Hz}$ & $-0.29 \pm 0.22$ & -0.63 & .003 \\
\hline Inspiration & $-0.29 \pm 0.22$ & -0.64 & .002 \\
\hline Expiration & $-0.28 \pm 0.27$ & -0.56 & .01 \\
\hline Resistance at $20 \mathrm{~Hz}$ & $-0.09 \pm 0.10$ & -0.28 & .23 \\
\hline Inspiration & $-0.08 \pm 0.09$ & -0.25 & .30 \\
\hline Expiration & $-0.10 \pm 0.11$ & -0.21 & .36 \\
\hline Resistance at $5 \mathrm{~Hz}$ and $20 \mathrm{~Hz}$ & $-0.19 \pm 0.17$ & -0.63 & .003 \\
\hline Inspiration & $-0.20 \pm 0.18$ & -0.65 & .002 \\
\hline Expiration & $-0.19 \pm 0.21$ & -0.53 & .02 \\
\hline Reactance at $5 \mathrm{~Hz}$ & $0.21 \pm 0.27$ & 0.64 & .002 \\
\hline Inspiration & $0.18 \pm 0.24$ & 0.56 & .01 \\
\hline Expiration & $0.24 \pm 0.34$ & 0.68 & .001 \\
\hline Reactance at $20 \mathrm{~Hz}$ & $0.12 \pm 0.08$ & 0.62 & .004 \\
\hline Inspiration & $0.13 \pm 0.09$ & 0.40 & .08 \\
\hline Expiration & $0.12 \pm 0.12$ & 0.61 & .004 \\
\hline Resonance frequency & $-10.61 \pm 7.73$ & -0.31 & .18 \\
\hline
\end{tabular}

* The mean \pm SD change in modified Medical Research Council dyspnea score was $-1.5 \pm$ 0.8 .

$\mathrm{PEF}=$ peak expiratory flow

$\mathrm{FEF}_{50}=$ forced expiratory flow at $50 \%$ of the $\mathrm{FVC}$ maneuver

$\mathrm{FEF}_{25}=$ forced expiratory flow at $25 \%$ of the FVC maneuver

tion measurement changes and dyspnea scores were evaluated with the Spearman correlation test.

\section{Results}

\section{Subjects}

The 20 subjects ( 16 male, 4 female) had a mean age of $59.1 \pm 14.3$ years, a mean body weight of $52.3 \pm 13.4 \mathrm{~kg}$, and a mean height of $161.9 \pm 7.7 \mathrm{~cm}$. Three subjects with benign variable $\mathrm{CAO}$ had tracheomalacia due to relapsing polychondritis and post-tuberculosis stricture. Seven subjects had variable CAO and malignant disease with extrinsic compression resulting from a primary tumor and associated enlarged lymph nodes. Ten subjects with fixed CAO had malignant disease (4 lung cancers, 4 esophageal cancers, 1 tracheal cancer, and 1 adenoid cystic carcinoma). Eighteen subjects required stent insertion. For the 2 subjects who did not receive a stent, 1 required balloon dilation and the other required argon plasma coagulation.

\section{Symptoms and Pulmonary Function Before and After Interventional Bronchoscopy}

After the interventional bronchoscopy, the mean dyspnea score decreased from $3.0 \pm 0.6$ to $1.5 \pm 0.5(P<.001)$, 
Table 4. Dyspnea Score, Pulmonary Function Measurements, and Collapsibility Index for Variable and Fixed Central Airway Obstruction Before Interventional Bronchoscopy

\begin{tabular}{|c|c|c|c|}
\hline & $\begin{array}{l}\text { Variable } \\
\text { Central Airway } \\
\text { Obstruction } \\
(n=10)\end{array}$ & $\begin{array}{l}\text { Fixed } \\
\text { Central Airway } \\
\text { Obstruction } \\
(n=10)\end{array}$ & $P$ \\
\hline Dyspnea score & $3.3 \pm 0.5$ & $2.6 \pm 0.52$ & .01 \\
\hline FVC, L & $2.09 \pm 0.61$ & $2.71 \pm 0.86$ & .14 \\
\hline $\mathrm{FEV}_{1}, \mathrm{~L}$ & $0.81 \pm 0.39$ & $1.39 \pm 0.62$ & .03 \\
\hline $\mathrm{PEF}, \mathrm{L} / \mathrm{s}$ & $1.64 \pm 0.57$ & $2.54 \pm 1.02$ & .04 \\
\hline $\mathrm{FEF}_{50}, \mathrm{~L} / \mathrm{s}$ & $0.56 \pm 0.40$ & $1.29 \pm 0.73$ & .01 \\
\hline $\mathrm{FEF}_{25}, \mathrm{~L} / \mathrm{s}$ & $0.39 \pm 0.31$ & $0.66 \pm 0.39$ & .11 \\
\hline Resistance at $5 \mathrm{~Hz}, \mathrm{kPa} / \mathrm{L} / \mathrm{s}$ & $0.88 \pm 0.23$ & $0.45 \pm 0.12$ & .001 \\
\hline Inspiration & $0.77 \pm 0.29$ & $0.43 \pm 0.12$ & $<.001$ \\
\hline Expiration & $0.89 \pm 0.26$ & $0.46 \pm 0.13$ & .001 \\
\hline Resistance at $20 \mathrm{~Hz}, \mathrm{kPa} / \mathrm{L} / \mathrm{s}$ & $0.40 \pm 0.09$ & $0.36 \pm 0.09$ & .38 \\
\hline Inspiration & $0.37 \pm 0.08$ & $0.34 \pm 0.08$ & .30 \\
\hline Expiration & $0.44 \pm 0.10$ & $0.38 \pm 0.10$ & .17 \\
\hline Resistance at $5 \mathrm{~Hz}-$ Resistance at $20 \mathrm{~Hz}, \mathrm{kPa} / \mathrm{L} / \mathrm{s}$ & $0.46 \pm 0.14$ & $0.08 \pm 0.05$ & $<.001$ \\
\hline Inspiration & $0.50 \pm 0.26$ & $0.09 \pm 0.05$ & $<.001$ \\
\hline Expiration & $0.45 \pm 0.20$ & $0.08 \pm 0.05$ & $<.001$ \\
\hline Reactance at $5 \mathrm{~Hz}, \mathrm{kPa} / \mathrm{L} / \mathrm{s}$ & $-0.56 \pm 0.43$ & $-0.14 \pm 0.05$ & $<.001$ \\
\hline Inspiration & $-0.51 \pm 0.37$ & $-0.14 \pm 0.04$ & $<.001$ \\
\hline Expiration & $-0.65 \pm 0.48$ & $-0.13 \pm 0.08$ & $<.001$ \\
\hline Reactance at $20 \mathrm{~Hz}, \mathrm{kPa} / \mathrm{L} / \mathrm{s}$ & $-0.17 \pm 0.10$ & $-0.01 \pm 0.05$ & .002 \\
\hline Inspiration & $-0.18 \pm 0.10$ & $-0.02 \pm 0.05$ & .001 \\
\hline Expiration & $-0.19 \pm 0.12$ & $-0.01 \pm 0.06$ & .003 \\
\hline Resonance frequency, L/s & $32.04 \pm 8.23$ & $20.29 \pm 7.63$ & .009 \\
\hline Collapsibility index, $\%$ & $75.8 \pm 14.5$ & $12.0 \pm 9.3$ & $<.001$ \\
\hline $\begin{array}{l}\text { Values are mean } \pm \mathrm{SD} . \\
\mathrm{PEF}=\text { peak expiratory flow } \\
\mathrm{FEF}_{50}=\text { forced expiratory flow at } 50 \% \text { of the } \mathrm{FVC} \text { maneuver } \\
\mathrm{FEF}_{25}=\text { forced expiratory flow at } 25 \% \text { of the } \mathrm{FVC} \text { maneuver }\end{array}$ & & & \\
\hline
\end{tabular}

and the airway lumen cross-sectional area at the narrowest segment significantly increased from $52.3 \pm 31.8 \mathrm{~m}^{2}$ to $101.1 \pm 31.3 \mathrm{~m}^{2}(P<.001)$ (Table 1$)$. Pulmonary function measurements also significantly improved, especially peak expiratory flow, which increased from $2.09 \pm 0.93 \mathrm{~L} / \mathrm{s}$ to $4.48 \pm 2.05 \mathrm{~L} / \mathrm{s}(P<.001)$, resistance at $5 \mathrm{~Hz}$, which decreased from $0.67 \pm 0.29 \mathrm{kPa} / \mathrm{L} / \mathrm{s}(P<.001)$ to $0.38 \pm 0.17 \mathrm{kPa} / \mathrm{L} / \mathrm{s}$, and reactance at $20 \mathrm{~Hz}$, which increased from $-0.09 \pm 0.11$ to $0.03 \pm 0.08(P<.001)$. Table 2 shows the correlations between the pre-intervention dyspnea scores and the baseline pulmonary function measurements. There were correlations between pre-intervention dyspnea score and baseline spirometry values, except for FVC; however, there were no correlations between the change in dyspnea score and spirometry values (Table 3). The reason for this is that the dyspnea score had a smaller change because of the 5-point scale, and baseline spirometry was different for each $\mathrm{CAO}$ subject. As a result, the changes in spirometry showed variations after treatment.
On the other hand, resistance at $5 \mathrm{~Hz}$, resistance 5$20 \mathrm{~Hz}$, and reactance at $5 \mathrm{~Hz}$ were significantly correlated with improved dyspnea score (see Table 3). The reason for this is that baseline impulse oscillometry was slightly different for CAO subjects, and the correlation between impulse oscillometry parameters and dyspnea score before treatment was similar to the correlation between the change in impulse oscillometry parameters and the change in dyspnea score. The type of obstruction correlated with the dyspnea score $(P=.07)$ (Table 4$)$.

\section{Impulse Oscillometry Analysis for Fixed and Variable Obstruction}

Diagnosis of CAO was made by a combination of chest CT and bronchoscopy. All 20 subjects had abnormal flow-volume curves. Via bronchoscopy we confirmed fixed CAO in 10 subjects, and variable CAO in 10 subjects, but the flow-volume curves showed fixed obstruction pattern in 15 subjects and variable obstruction pattern in 5 subjects. Namely, of the 10 variable CAO cases con- 

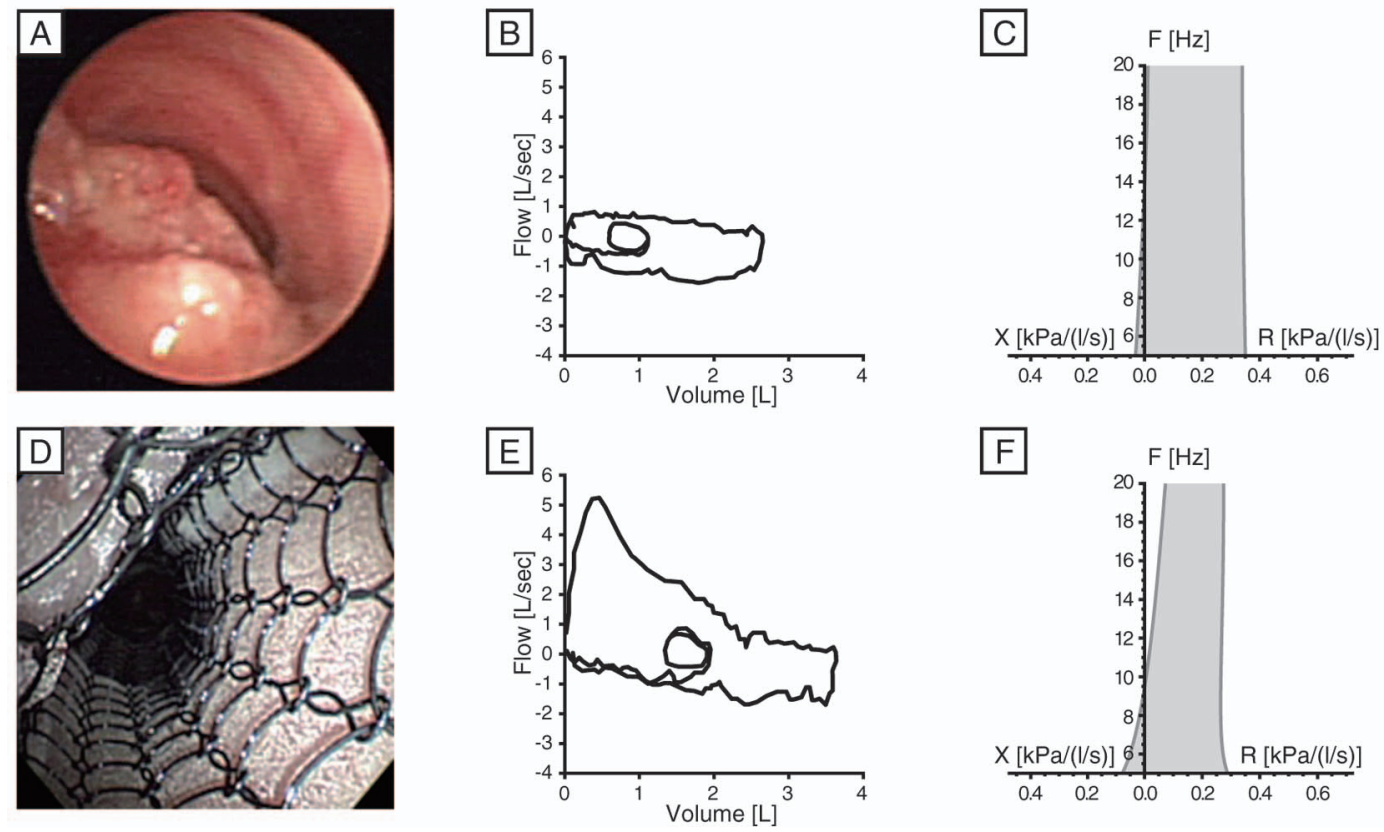

Fig. 1. Before stenting, bronchoscopy (A) shows a fixed central airway obstruction (CAO) during expiration. The flow-volume curve (B) shows the pattern typical of fixed CAO. Impulse oscillometry (C) shows that the respiratory resistance at $20 \mathrm{~Hz}$ displays a similar increase to the resistance at $5 \mathrm{~Hz}$, and respiratory reactance is within the normal range. After placement of a covered, expanding metal stent, bronchoscopy (D) shows restored airway patency, the flow-volume curve (E) shows major improvement, and impulse oscillometry (F) shows slight improvement.
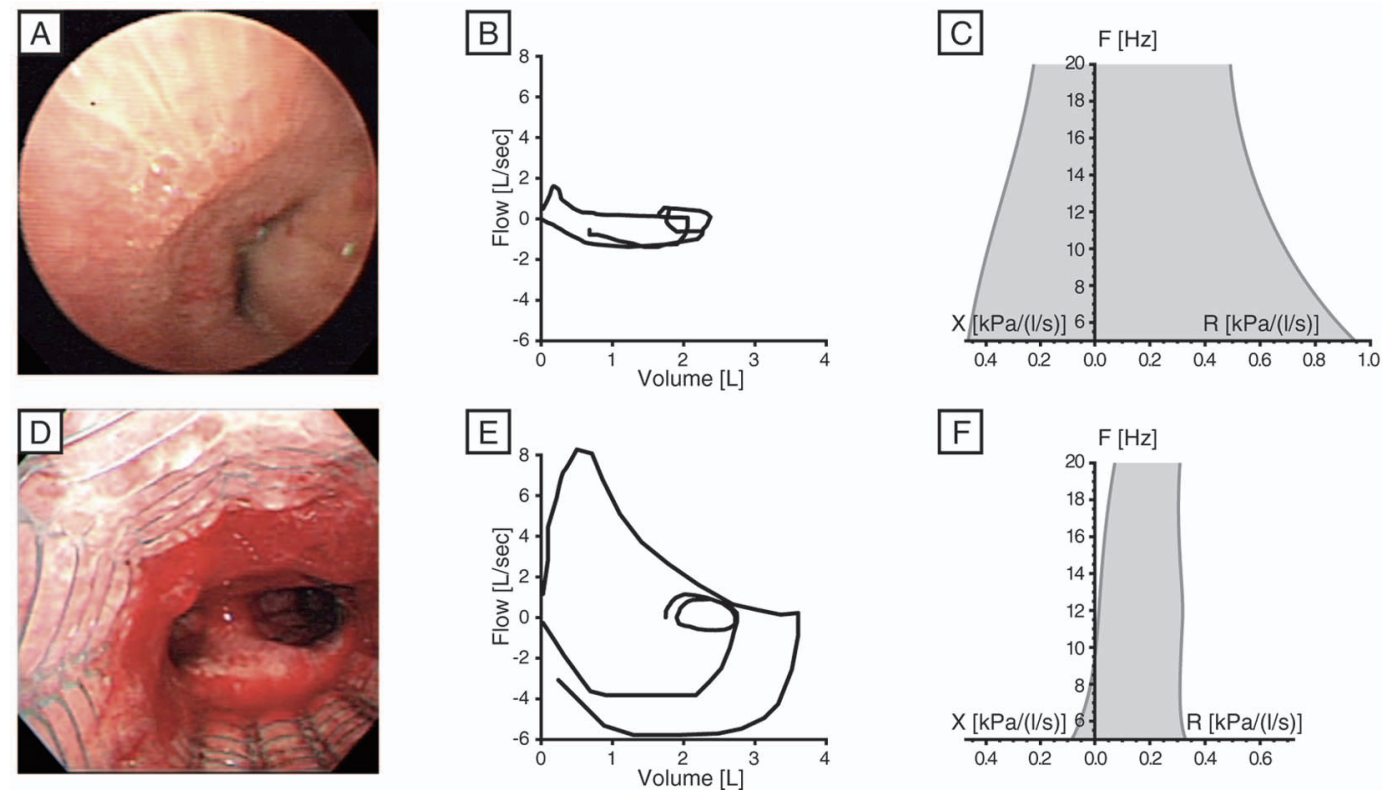

Fig. 2. Before stenting, bronchoscopy (A) shows variable central airway obstruction $(C A O)$ during expiration. The flow-volume curve (B) shows the pattern typical of variable CAO. The flow-volume loop (C) suggests a fixed obstruction, because of air-flow limitation during both inspiration and expiration, but in this case the obstruction was due to tracheobronchomalacia and airway collapse due to relapsing polychondritis, which is a classic type of dynamic intrathoracic airway obstruction, and the flow-volume curve (B) shows worsened flow limitation during expiration. Impulse oscillometry $(C)$ shows frequency dependence of resistance and the decrease in respiratory reactance seen in variable CAO. After placement of an expanding metal stent, bronchoscopy (D) shows restored airway patency, and both the flow-volume curve $(E)$ and impulse oscillometry $(F)$ show improvement.

firmed via bronchoscopy, 8 showed fixed obstruction pattern on flow-volume curve. Of the 10 fixed obstruction cases confirmed via bronchoscopy, 3 showed variable obstruction pattern on the flow-volume curve. All the CAO 

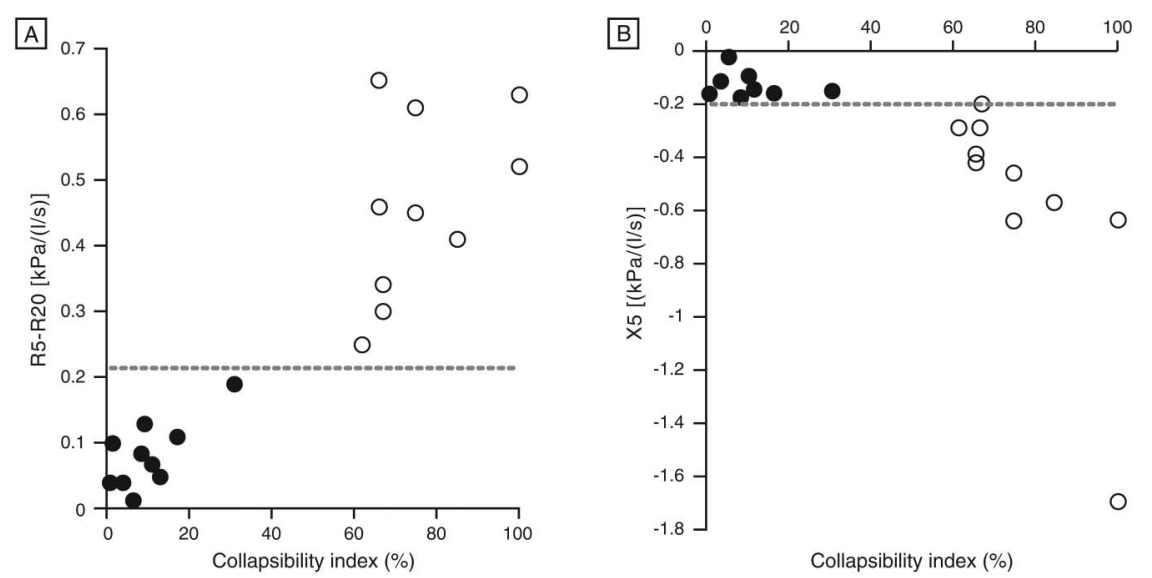

Fig. 3. Collapsibility index (the difference in airway lumen size between inspiration and expiration) versus 2 impulse oscillometry values: the difference between respiratory resistance at $5 \mathrm{~Hz}$ and resistance at $20 \mathrm{~Hz}$, and reactance at $5 \mathrm{~Hz}$. Variable central airway obstruction (CAO) was defined as a collapsibility index $>50 \%$, and fixed CAO was defined as a collapsibility index $<50 \%$. Subjects with variable CAO showed a marked increase in the difference between respiratory resistance at $5 \mathrm{~Hz}$ and $20 \mathrm{~Hz}(P<.001)$, compared to subjects with fixed $\mathrm{CAO}$, with a threshold above $0.21 \mathrm{kPa} / \mathrm{L} / \mathrm{s}$, and reactance at $5 \mathrm{~Hz}$ showed a significant difference between variable and fixed CAO $(P<.001)$, with a threshold below $-0.19 \mathrm{kPa} / \mathrm{L} / \mathrm{s}$.

was intrathoracic, and the variable collapse was expiratory in nature.

In one subject with fixed CAO due to lung cancer, the flow-volume curve showed marked reduction of inspiratory and expiratory flow, with a plateau (Fig. 1A and 1B). Impulse oscillometry showed that the respiratory resistance at $5 \mathrm{~Hz}$ and $20 \mathrm{~Hz}$ had similar increases and that respiratory reactance was within the normal range (see Fig. 1C). After placement of an expanding metal stent, spirometry and impulse oscillometry findings improved (see Figs. 1D-F).

In one subject with variable $\mathrm{CAO}$ due to tracheomalacia with relapsing polychondritis, bronchoscopy showed expiratory central airway collapse (Fig. 2A), and the flowvolume curve showed severe reduction of expiratory flow compared to inspiratory flow (see Fig. 2B). Impulse oscillometry showed that the respiratory resistance spectrum became lower at higher frequencies and that respiratory reactance was reduced to the abnormal range (see Fig. 2C). After placement of a self-expanding metal stent, airway patency was restored and pulmonary function measurements showed marked improvement (see Fig. 2D-F).

Table 4 compares the variable and fixed CAO. For resistance at $5 \mathrm{~Hz}$ and resistance $5-20 \mathrm{~Hz}$ there was a significant difference between variable and fixed $\mathrm{CAO}$ $(P=.009$ and $P<.001$, respectively). The resistance at $20 \mathrm{~Hz}$ showed no significant difference between variable and fixed CAO $(P=.19)$. Resistance $5-20 \mathrm{~Hz}$ showed a major difference between variable CAO $(0.46 \pm 0.14$ $\mathrm{kPa} / \mathrm{L} / \mathrm{s})$ and fixed CAO $(0.08 \pm 0.10 \mathrm{kPa} / \mathrm{L} / \mathrm{s})$, and a value over $0.21 \mathrm{kPa} / \mathrm{L} / \mathrm{s}$ was defined as the threshold for variable CAO (Fig. 3A). There was a significant difference in reactance at $5 \mathrm{~Hz}$ versus and at $20 \mathrm{~Hz}$ between variable CAO and fixed CAO $(P<.001$ and $P<.008$, respectively). The receiver operating characteristic curve showed sensitivity and specificity of $100 \%$ for both resistance $5-20 \mathrm{~Hz}$ and reactance at $5 \mathrm{~Hz}$. Resonance frequency showed a nonsignificant difference between variable and fixed $\mathrm{CAO}(P=.08)$. Reactance at $5 \mathrm{~Hz}$ showed a marked difference between variable $\mathrm{CAO}(-0.56 \pm 0.43$ $\mathrm{kPa} / \mathrm{L} / \mathrm{s})$ and fixed CAO $(-0.14 \pm 0.05 \mathrm{kPa} / \mathrm{L} / \mathrm{s})$, and a value under $-0.19 \mathrm{kPa} / \mathrm{L} / \mathrm{s}$ was defined as the threshold for variable $\mathrm{CAO}$ (see Fig. 3B). Inspiratory and expiratory resistance at $5 \mathrm{~Hz}$ and reactance at $5 \mathrm{~Hz}$ were greater in subjects with variable $\mathrm{CAO}$ than in subjects with fixed $\mathrm{CAO}$; however, only minimal changes were seen in the remaining impulse oscillometry measurements between inspiration and expiration for both variable and fixed CAO.

\section{Discussion}

Our results demonstrate that impulse oscillometry is a valuable addition to spirometry for diagnosis and monitoring of fixed and variable CAO before and after bronchoscopic interventions. Impulse oscillometry may be particularly useful in patients with serious pulmonary symptoms (severe dyspnea, cough, stridor, and hemoptysis), profound fatigue, language barriers, or cognitive impairment, who cannot properly execute forced expiratory maneuvers. Impulse oscillometry is an effort-independent test performed during tidal breathing, does not cause respiratory fatigue, and, as suggested by this study, may be more sensitive than spirometry for discriminating variable from fixed CAO. Resistance $5-20 \mathrm{~Hz}$ and reactance at $5 \mathrm{~Hz}$ proved to be valuable markers for discriminating between variable and fixed $\mathrm{CAO}$. For variable $\mathrm{CAO}$, re- 
spiratory resistance showed marked frequency dependence, whereas it was nearly constant for all frequencies in fixed CAO. The pattern of frequency dependence of resistance in variable $\mathrm{CAO}$ is much like that of an upper airway shunt. ${ }^{23-25}$ or as is seen in patients with COPD, in whom the resistance at $5 \mathrm{~Hz}$ is higher than the resistance at $20 \mathrm{~Hz} \cdot{ }^{23,26-28}$

When forced oscillations are applied to measure the impedance of the respiratory system, part of the air flow generated by the loudspeaker does not enter the lower airways and is lost in motions of the upper airway walls. This process is called an upper airway shunt, which causes changes in the estimation of respiratory impedance. In variable $\mathrm{CAO}$ a compliant central airway allows shunting to occur in higher frequency components, but there is a difference between inspiratory and expiratory lower frequency components. In contrast, in fixed CAO the minimal compliance of the central airway is not sufficient to shunt higher frequency components, thereby keeping resistance high so there is no difference between the inspiratory and expiratory frequency components. The decrease in reactance at $5 \mathrm{~Hz}$ for variable $\mathrm{CAO}$ is consistent with the above discussion. In fixed CAO, lung compliance and central airway resistance mainly determine the reactance components. However, the reactance components in variable CAO are determined by airway compliance instead of lung compliance, resulting in a lower reactance at $5 \mathrm{~Hz}$ and a resulting difference between inspiratory and expiratory reactance at $5 \mathrm{~Hz}$.

In this study we used morphometric bronchoscopy to assess the type of CAO, and CT to determine the degree of airway narrowing. Morphometric bronchoscopy is also useful for identifying and quantifying fixed and variable $\mathrm{CAO}^{20,29}$; however, image analysis is not performed immediately, but post-procedure, with image processing software. Immediate quantification of the degree of CAO might be achieved in the future, with stereoscopic bronchoscopy. The collapsibility index, as defined in this study, has been previously proposed for tracheomalacia and excessive dynamic airway collapse. ${ }^{22}$ For the purpose of this study we used the collapsibility index to differentiate variable and fixed CAO. Variable CAO included tracheomalacia and extrinsic compression by tumor. Generally, tracheomalacia, which is a form of excessive dynamic airway collapse, is identified as a $>50 \%$ reduction in the cross-sectional area of the airway between inspiration and expiration. This criterion, however, may lead to a false positive diagnosis if applied during coughing or forced expiration. ${ }^{30} \mathrm{We}$ therefore calculated the collapsibility index from images obtained during spontaneous tidal breathing.

Our results show that the change in resistance $5-20 \mathrm{~Hz}$ had the best sensitivity and specificity of the pulmonary function test results. For example, patients with CAO and profound weakness or dyspnea may be better candidates for impulse oscillometry than for spirometry. The ability to objectively assess dyspnea in these patients can be important in treatment decision-making (conservative, minimally invasive, open surgery), proper documentation, and meaningful research. In our study the impulse oscillometry values (but not the spirometry values) correlated with the dyspnea scores. This finding is in agreement with other studies, which found that that dyspnea score is highly sensitive to the presence of varying degrees of laryngotracheal stenosis, and that there was only weak correlation between dyspnea score and spirometry variables. ${ }^{8}$ Similar observations were found in COPD patients, in whom there is a strong correlation between dyspnea score and disability, but weaker correlations between dyspnea score and $\mathrm{FEV}_{1}$ or peak expiratory flow. Impulse oscillometry may therefore be preferable for these patients, because of its better sensitivity and because patients with CAO may not be able to perform forced expiratory maneuvers.

We also found limitations of impulse oscillometry in patients with CAO. For instance, in the subjects with variable $\mathrm{CAO}$, resistance $5-20 \mathrm{~Hz}$ and reactance at $5 \mathrm{~Hz}$ were similar to those in subjects with severe COPD and tidal expiratory flow limitation; this limits the application of these parameters in distinguishing severe COPD from variable CAO. In the present study the usefulness of impulse oscillometry was assumed to be based on the fact that the resistance obtained at a high frequency preferentially reflects the large central airways, and therefore a change in the frequency dependence of resistance can be considered to reflect the change in the large or small airways. However, the airway resistance is distributed heterogeneously across the airways, and this heterogeneity may affect low frequencies more than high frequencies, creating an additional source of frequency dependence that, in principle, is not a reflection of airway size. This is exemplified in this study, which showed that the frequency dependence of resistance was actually similar to COPD and in some subjects with CAO. Another limitation of impulse oscillometry (as with any noninvasive physiologic assessment) is the inability to precisely localize the narrowest airway segment responsible for flow limitation. This is especially relevant when the flow limiting segments are difficult to identify, such as in patients with excessive dynamic airway collapse. For this purpose, the use of intraluminal airway pressure catheter measurements distal and proximal to the narrowed airway during tidal breathing allows immediate intraoperative estimation of the physiologic benefits of a bronchoscopic intervention. ${ }^{21}$

We did not measure forced inspiratory flow at 50\%, the ratio of forced expiratory flow at $50 \%$ to forced inspiratory flow at $50 \%$, or the ratio of $\mathrm{FEV}_{1}$ to peak expiratory flow. While usually only diagnostic of central/upper-airway obstruction in cases of severe airway narrowing, these measurements could have allowed us to define variable and 
fixed obstruction based on spirometry data, and might have permitted correlations with the impulse oscillometry variables. While the mean $\mathrm{FEV}_{1} / \mathrm{FVC}$ of 0.42 prior to bronchoscopic intervention might suggest underlying obstructive ventilatory impairment such as asthma or COPD, we believe that the significant post-intervention $\mathrm{FEV}_{1} / \mathrm{FVC}$ improvement (to 0.70) suggests that the CAO was the main culprit for the spirometry findings, which highlights once more spirometry's lack of specificity for detecting CAO. In addition, in COPD, frequency dependence of respiratory resistance indicates ventilation disturbance, and reactance at $5 \mathrm{~Hz}$ can detect tidal air-flow limitation. Tracheobronchomalacia is a typical example of variable obstruction. It remains unclear whether impulse oscillometry can distinguish between COPD patients with and without tracheobronchomalacia.

\section{Conclusions}

Our study adds to the body of evidence supporting the use of impulse oscillometry for physiologic assessment of patients with CAO. ${ }^{15-18}$ Although impulse oscillometry may not be the ultimate test to distinguish between small and large airway processes, or the solution to anatomically localize flow-limiting bronchial segments in patients with $\mathrm{CAO}$, it is noninvasive, effort-independent, can usually differentiate fixed from variable obstruction, and is useful for assessing CAO before and after interventional bronchoscopy. Larger scale studies should clarify whether impulse oscillometry is more sensitive than spirometry for differentiating fixed from variable obstruction, and more sensitive than spirometry for detecting CAO.

\section{ACKNOWLEDGMENTS}

We thank Jason Tonge, St Marianna University School of Medicine, for his help in manuscript preparation.

\section{REFERENCES}

1. Miller RD, Hyatt RE. Evaluation of obstructing lesions of the trachea and larynx by flow-volume loops. Am Rev Respir Dis 1973;108(3): 475-481.

2. Rotman HH, Liss HP, Weg JG. Diagnosis of upper airway obstruction by pulmonary function testing. Chest 1975;68(6):796-799.

3. Vergnon JM, Costes F, Bayon MC, Emonot A. Efficacy of tracheal and bronchial stent placement on respiratory functional tests. Chest 1995;107(3):741-746.

4. Schuurmans MM, Michaud GC, Diacon AH, Bolliger CT. Use of an ultrathin bronchoscope in the assessment of central airway obstruction. Chest 2003;124(2):735-739.

5. Miyazawa T, Miyazu Y, Iwamoto Y, Ishida A, Kanoh K, Sumiyoshi $\mathrm{H}$, et al. Stenting at the flow-limiting segment in tracheobronchial stenosis due to lung cancer. Am J Respir Crit Care Med 2004; 169(10):1096-1102.
6. Handa H, Miyazawa T, Murgu SD, Nishine H, Kurimoto N, Huang $\mathrm{J}$, et al. Novel multimodality imaging and physiologic assessments clarify choke-point physiology and airway wall structure in expiratory central airway collapse. Respir Care 2012;57(4):634-641.

7. Miller RD, Hyatt RE. Obstructing lesions of the larynx and trachea: clinical and physiologic characteristics. Mayo Clin Proc 1969;44(3): 145-161.

8. Nouraei SA, Nouraei SM, Randhawa PS, Butler CR, Magill JC, Howard DJ, et al. Sensitivity and responsiveness of the Medical Research Council dyspnoea scale to the presence and treatment of adult laryngotracheal stenosis. Clin. Otolaryngol 2008;33(6):575-580.

9. Hyatt RE, Black LF. The flow-volume curve. A current perspective. Am Rev Respir Dis 1973;107(2):191-199.

10. Acres JC, Kryger MH. Clinical significance of pulmonary function tests: upper airway obstruction. Chest 1981;80(2):207-211.

11. Peslin R, Friedberg JJ. Oscillation mechanics of the respiratory system. In: Macklem PT, Mead J, editors. Handbook of physiology: the respiratory system, volume 3. Bethesda, MD: American Physiological Society; 1986:145-177.

12. Smith HJ, Reinhold P, Goldman MD. Forced oscillation technique and impulse oscillometry. Eur Respir Mon 2005;31:72-105.

13. Pornsuriyasak P, Ploysongsang Y. Impulse oscillometry system in diagnosis of central airway obstruction in adults: comparison with spirometry and body plethysmography. Chest 2009;136(Suppl):123S.

14. Dubois AB, Brody AW, Lewis DH, Burgess BF Jr. Oscillation mechanics of lungs and chest in man. J Appl Physiol 1956;8(6):587-594.

15. Horan T, Mateus S, Beraldo P, Araújo L, Urschel J, Urmenyi E, et al. Forced oscillation technique to evaluate tracheostenosis in patients with neurologic injury. Chest 2001;120(1):69-73.

16. Verbanck S, de Keukeleire T, Schuermans D, Meysman M, Vincken W, Thompson B. Detecting upper airway obstruction in patients with tracheal stenosis. J Appl Physiol 2010;109(1):47-52.

17. Vicencio AG, Bent J, Tsirilakis K, Nandalike K, Veler H, Parikh S. Management of severe tracheal stenosis using flexible bronchoscopy and impulse oscillometry. J Bronchol Intervent Pulmonol 2010;17(2): 162-164.

18. Handa $\mathrm{H}$, Mineshita M, Miyazawa T. Impulse oscillometry in malignant tracheal stenosis (abstract). Chest 2010;138:921A.

19. Oostveen E, MacLeod D, Lorino H, Farré R, Hantos Z, Desager K, et al. The forced oscillation technique in clinical practice: methodology, recommendations and future developments. Eur Respir J 2003; 22(6):1026-1041.

20. Matsuoka S, Kurihara Y, Yagihashi K, Hoshino M, Nakajima Y. Airway dimensions at inspiratory and expiratory multisection CT in chronic obstructive pulmonary disease: correlation with airflow limitation. Radiology 2008;248(3):1042-1049.

21. Nishine H, Hiramoto T, Kida H, Matsuoka S, Mineshita M, Kurimoto $\mathrm{N}$, et al. Assessing the site of maximal obstruction in the trachea using lateral pressure measurement during bronchoscopy. Am J Respir Crit Care Med 2012;185(1):24-33.

22. Murgu S, Colt HG. Morphometric bronchoscopy in adults with central airway obstruction: case illustrations and review of the literature. Laryngoscope 2009;119(7):1318-1324.

23. Mead J. Contribution of compliance of airways to frequencydependent behavior of lungs. J Appl Physiol 1969;26(5):670-673.

24. Michaelson ED, Grassman ED, Peters WR. Pulmonary mechanics by spectral analysis of forced random noise. J Clin Invest 1975;56(5): 1210-1230.

25. Cauberghs M, Van de Woestijne KP. Effect of upper airway shunt and series properties on respiratory impedance measurements. J Appl Physiol 1989;66(5):2274-2279.

26. Grimby G, Takishima T, Graham W, Macklem P, Mead J. Frequency dependence of flow resistance in patients with obstructive lung disease. J Clin Invest 1968;47(6):1455-1465. 
27. Goldman MD, Saadeh C, Ross D. Clinical applications of forced oscillation to assess peripheral airway function. Respir Physiol Neurobiol 2005;148(1-2):179-194.

28. van Noord JA, Wellens W, Clarysse I, Cauberghs M, Van de Woestijne KP, Demedts M. Total respiratory resistance and reactance in patients with upper airway obstruction. Chest 1987;92(3):475480 .
29. Loring SH, O'donnell CR, Feller-Kopman DJ, Ernst A. Central airway mechanics and flow limitation in acquired tracheobronchomalacia. Chest 2007;131(4):1118-1124.

30. Boiselle PM, O'Donnell CR, Bankier AA, Ernst A, Millet ME, Potemkin A, et al. Tracheal collapsibility in healthy volunteers during forced expiration: assessment with multidetector CT. Radiology 2009;252(1):255-262. 